\title{
ELI SA based monitoring and analysis of tetracycline residues in cattle milk in various districts of Punjab
}

\author{
Abhishek Gaurav, J. P. S. Gill, R. S. Aulakh and J. S. Bedi \\ School of Public Health and Zoonoses, \\ Guru Angad Dev Veterinary and Animal Science University(GADVASU), Ludhiana - 141004, Punjab, India \\ Corresponding author: Abhishek Gaurav, email: gaurav.vets@yahoo.com \\ Received: 13-10-2013, Revised: 06-12-2013, Accepted: 09-12-2013, Published online: 22-01-2014
}

doi: $10.14202 /$ vetworld.2014.26-29

How to cite this article: Gaurav A, Gill JPS, Aulakh RS and Bedi JS (2014) ELISA based monitoring and analysis of tetracycline residues in cattle milk in Punjab, Veterinary World 7(1): 26-29.

\section{Abstract}

Background: Tetracycline antibiotics are widely used for prevention and control of disease. However, the presence of tetracycline antibiotics residues in food is a serious public health concern because of the harmful effects of these residues on consumer's health. Therefore, it is necessary to detect tetracycline residues in food of animal origin keeping in view the food safety issues and problem related to antibiotic resistance.
\end{abstract}

Aim: To investigate and monitor the occurrence of tetracycline residues in cattle milk in five districts of Punjab.

Materials and Methods: In this study, a total of 133 cattle milk samples were collected from dairies of 5 districts of Punjab state, India in May, 2013 and were tested and analyzed for their contamination status with tetracycline residues.

Results: Out of these 133 milk samples analyzed, 18 samples were found to contain tetracycline residues. The percentages of tetracycline detected in the samples from 5 districts were in the range of $0-46.15 \%$. The concentration of tetracycline residues in cattle milk samples were found to be in the range 16-134.5 ppb.

Conclusions: Three samples exceeded the maximum recommended tetracycline antibiotic residue levels (MRLs) as prescribed by the European Union and the Codex Alimentarius Commission .

Key words: antibiotic residues, ELISA, milk, Punjab, tetracycline.

\section{I ntroduction}

Antibiotic residues in foods of animal origin are one of the sources of concern among the public and medical health professionals [1]. Antibiotics are used to treat infections in sick and injured animals and as prophylactics and growth promoters in lower concentrations than those used for treatment that is a potentially dangerous practice since it can encourage the production of antibiotic resistant strains of bacteria $[2,3]$. Side effects from tetracyclines are not common, but of particular note is phototoxicity. Therefore, to protect consumers, regulatory agencies in the European Union published several of? cial documents regulating the control of veterinary drugs in food products from animal origin. Tolerance levels, as described by European Commission Regulation 470/2009/EC [4], were set for compounds that can be used for therapeutic purposes. The MRLs set for the tetracyclines by European Union is $100 \mu \mathrm{g} / \mathrm{kg}$. Regulation 37/2010 [5] also lists pharmacologically active substances and their maximum residue level (MRL) in foodstuffs of animal origin.

For the simultaneous analysis of compounds of different antibiotic classes in a multi-class residue analysis, only a restricted number of methods are reported

Copyright: The authors. This article is an open access article licensed under the terms of the Creative Commons Attribution License (http://creativecommons.org/licenses/by/2.0) which permits unrestricted use, distribution and reproduction in any medium, provided the work is properly cited.

Veterinary World, EISSN: 2231-0916 in the literature, mainly due to difficulties related to differences in physico-chemical properties between families of compounds [6-12]. However, there are several methods to detect tetracyclines but chromatography including high performance liquid chromatography and liquid chromatography $[13,14]$ are the efficient techniques. This efficiency can be gathered in multi-detection methods based on liquid chromatography coupled with tandem mass spectrometry [15-18]. Microbiological and bioassay techniques are still used for antibiotic qualitative screening purposes [19-23] mainly because of their low cost and simplicity; however, they lack sensitivity and specificity. In this study, competitive enzyme immunoassay technique was used to determine tetracycline residues in milk. This technique has the advantage that it does not include cleanup and extraction procedure of sample as is needed in chromatography techniques. In addition, this technique is time saving as it provides optimal limit of detection (LOD) and reproducibility in a complex milk matrix in a very short span of time.

This study was undertaken with the aim of monitoring of tetracycline residues in milk samples from Punjab by employing ELISA technique, as it is the most commonly used antibiotic on dairy farms.

\section{Materials and Methods}

Collection of milk samples: In total 133 individual animal milk samples were collected from 5 districts of Punjab viz., Ludhiana, Muktsar, Ferozpur, Amritsar 
Table-1. District wise samples detected positive with their mean, maximum and MRL values

\begin{tabular}{|c|c|c|c|c|c|}
\hline $\begin{array}{l}\text { Name of } \\
\text { District }\end{array}$ & $\begin{array}{c}\text { Total No. of } \\
\text { samples analyzed }\end{array}$ & $\begin{array}{l}\text { No. of samples } \\
\text { detected positive }\end{array}$ & $\begin{array}{c}\text { Mean residue } \\
(\mu \mathrm{g} / \mathrm{kg})\end{array}$ & $\begin{array}{c}\text { Maximum residue } \\
(\mu \mathrm{g} / \mathrm{kg})\end{array}$ & $\begin{array}{c}\text { No. of samples } \\
\text { found above MRL }\end{array}$ \\
\hline Amritsar & 26 & 2 & 28.72 & 41.44 & Nil \\
\hline Patiala & 26 & 12 & 65.99 & 134.5 & 3 \\
\hline Ferozpur & 32 & 4 & 39.46 & 40.96 & Nil \\
\hline Ludhiana & 24 & Nil & Nil & Nil & Nil \\
\hline Muktsar & 25 & Nil & Nil & Nil & Nil \\
\hline Total & 133 & 18 & 44.72 & 134.5 & 3 \\
\hline
\end{tabular}

and Patiala. These collected samples were transported to the laboratory at $4^{\circ} \mathrm{C}$ and were preserved at $-20^{\circ} \mathrm{C}$, to conduct further analysis. These samples were tested and analyzed for tetracycline residues by using RIDASCREEN competitive enzyme immunoassay kits (Biopharm AG, Darmstadt, Germany). These milk samples were initially thawed and then centrifuged at $3000 \mathrm{~g}$ for $10 \mathrm{~min}$ for quanti-tative estimation of tetracycline. The upper cream layer was removed from the centrifuged milk samples and the skimmed milk samples were diluted in a ratio of 1:10 with sample dilution buffer $(50 \mu 1$ milk $+450 \mu \mathrm{l}$ buffer $)$ provided in kits. A $50 \mu 1$ aliquot from this dilution was used per well of ELISA plate in the test.

Antibiotic assay: RIDASCREEN (Biopharm AG, Darmstadt, Germany) tetracycline kit was used for the monitoring of the tetracycline residues from milk. This kit is a competitive enzyme immunoassay for the quantitative analysis of tetracycline, minocycline, rolitetracycline, chlortetracycline and oxytetracycline in milk, honey and meat. All the reagents required for the enzyme immunoassay including standards were contained in the test kit. Each kit contained sufficient materials for 96 measurements. Each test kit contained 12 strips with 8 removable wells each, standard concentrations $(0,0.15,0.45,1.35,4.05 \mathrm{ppb}$ in aqueous solutions), conjugate (peroxidase conjugated secondary antibodies), anti-tetracycline antibody, substrate (containing urea peroxide), chromogen (containing tetramethylbenzidine), stop solution ( $1 \mathrm{~N}$ sulfuric acid) and buffer (sample and standard dilution buffer).

Experimental methodology: The RIDASCREEN competitive enzyme immunoassay kit (Biopharm AG, Darmstadt, Germany) which is commercially available including LOD with $1.5 \mathrm{ppb}(\mu \mathrm{g} / \mathrm{L})$ was used according to the manufacturer's instructions for antibiotic determination in milk samples. A volume of $50 \mu \mathrm{l}$ of each standard solution or prepared sample was added to each well followed by $50 \mu \mathrm{l}$ of anti-tetracycline antibody solution. Plate was incubated at room temperature for 1 hr. Thereafter, three times washing was given by adding $250 \mu \mathrm{l}$ of washing buffer to each well and then $100 \mu \mathrm{l}$ of enzyme conjugate was added to each well. Plate was again incubated at room temperature for 15 min. Again washing was given three times by adding $250 \mu 1$ of washing buffer. Then, $50 \mu 1$ of substrate and $50 \mu \mathrm{l}$ of chromogen were added to each well and the plate was incubated in dark for $15 \mathrm{~min}$ at room temperature. Finally, $100 \mu 1$ of stop solution was added to stop the reaction and absorbance was recorded at 450 $\mathrm{nm}$ within 30 minute.

The results were calculated by obtaining the O.D. values and calculating the percentage (\%) absorbance. $\%$ absorbance $=$ Absorbance standard per sample/ Absorbance zero standard x 100.

Finally a calibration curve was plotted between the standard concentration and O.D. (Figure-1).

\section{Results and Discussion}

The objective of this study was to monitor and analyze the residual levels of tetracyclines in raw milk samples from Punjab. A total of 133 cattle milk samples were obtained from dairies of 5 districts of Punjab state, India in May, 2013 and assessed their contamination with tetracycline antibiotic, using the ELISA method to assess the exact residue levels in the dairy milk in the targeted area. The determined levels of tetracyclines residue in milk samples were then analyzed to compare the prevalent residue levels with recommended maximum permissible residue limits to find whether the prevalent residue levels are within the prescribed maximum limits in terms of consumer health protection. It was found that out of all the milk samples analyzed, 18 samples were found to contain tetracycline residues. The concentrations of tetracycline residues in cattle milk samples were in the range 16-134.5 ppb (Table-1). Three samples exceeded the maximum residue levels (MRLs) for tetracycline antibiotic, according to the regulations set by the European Union and the Codex Alimentarius Commission.

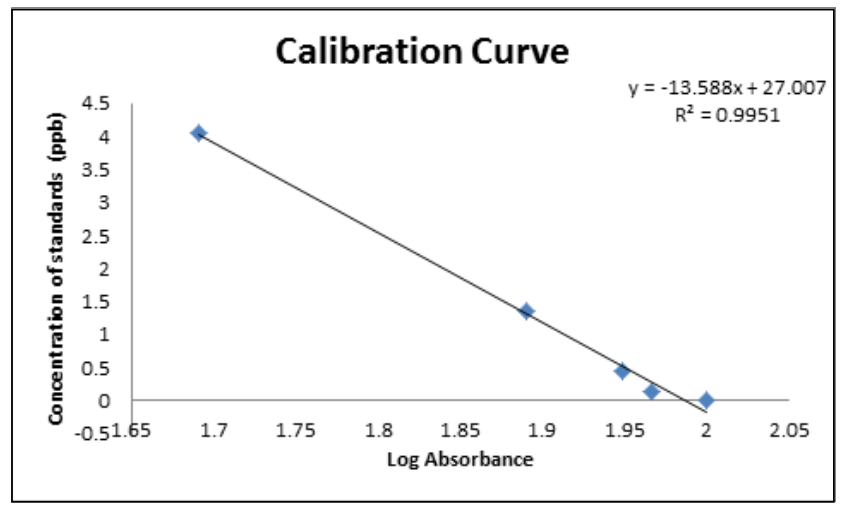

Fig. 1 Calibration curve for estimation of tetracycline by using ELISA

A study was conducted in which the screening of locally produced milk samples in Czech Republic indicated the presence of tetracyclines in $50.6 \%$ of the analyzed samples with concentrations under the MRL 
value [24]. In the present study, the highest tetracycline level detected has exceeded the MRL value and it was $134.5 \mu \mathrm{g} / \mathrm{kg}$. While in another study [25], the highest tetracycline level detected exceeding the MRL value was $149.1 \mu \mathrm{g} / \mathrm{kg}$.

Monitoring of locally produced and imported milk and dairy products collected in different seasonal periods from farms and retail outlets in Kuwait indicated that $29.1 \%$ of the analyzed fresh milk samples were above the MRL for tested residues with tetracycline as the dominant residue [26]. In a similar study conducted in Croatia [27], the highest tetracycline level detected was $49.5 \mu \mathrm{g} / \mathrm{kg}$. However, the mean tetracycline concentration $(2.83 \mu \mathrm{g} / \mathrm{kg})$ was more than 35 times lower than the MRLlevel.

A recent study was conducted [28] in which 94 samples of ultra-high temperature (UHT) milk and 26 samples of pasteurized milk from China's top dairy brands (I, II, III, IV), using the ELISA method were assessed for their contamination with tetracyclines. It was found that the percentage of UHT milk samples and pasteurized milk samples containing detectable levels of tetracyclines were 0 and $7.7 \%$ respectively. Occurrence of chloramphenicol, streptomycin and tetracycline residues in milk samples were also reported from Turkey [29], in which total 40 milk samples $(66.8 \%)$ were contaminated, out of a total of 60 milk samples analyzed. The high incidences of tetracycline were found in these samples. However, the tetracycline concentrations found were below the maximum residue limits permitted by the European Union [29].

\section{Conclusion}

Competitive ELISA was used to detect tetracycline residues in milk to monitor antibiotic residues. Out of total 133 milk samples analyzed, 18 samples were found to contain tetracycline residues with concentrations varying in the range 16-134.5 ppb. Three samples exceeded the maximum residue levels (MRLs) for tetracycline antibiotic, as per the established regulations set by the European Union and the Codex Alimentarius Commission. The methods used for antibiotic determination in milk by competitive immunoassay proved to be rapid and reliable.

Based on the findings of the study, the contamination level in milk samples were not alarming as only three samples out of total $133(2.3 \%)$ were found to exceed the MRL which on further dilution after pooling will not be having any adverse effect on human health. It suggests that the present status of tetracycline contamination is within specified limits but need continuous monitoring to take timely remedial actions to prevent its detrimental effects on public health.

\section{Author's contributions}

AG was research scholar who planned and conducted the study under supervision of JPSG, RSA and JSB. JPSG, RSA and JSB were member of advisory committee.

\section{Acknowledgements}

The author sincerely acknowledges the School of Public Health and Zoonoses, GADVASU, Ludhiana 141004 (Punjab) for providing laboratory and other facilities to conduct this study. Departmental fund of School of Public Health and Zoonosis was used for this study.

\section{References}

1. Bren, L. (2002) The Battle of the Bugs: Fighting Antibiotic Resistance. USDA Consumer Magazine 2002 Jul - Aug. http://www.fda.gov.fdac/features/2002/402_bugs.html. Accessed on 03-10-2013.

2. Khachatourians, G.G. (1998) Agricultural use of antibiotics and the evolution and transfer of antibiotic-resistant bacteria. JAMC., 159:1128-1136.

3. Simonsen G. S., Haaheim H., Dahl K. H., Kruse H., Lovseth A., Olsvik O. and Sundsfjord A. (1998) Transmission of Van A-type vancomycin resistant enterococciand Van A resistance elements between chicken and humans at avoparcin-exposedfarms. Microb Drug Resist Winter.,4(4): $313-318$.

4. European Commission. (2009) Regulation (EC) No. $470 / 2009$ of the European parliament and of the council of 6 May 2009: laying down community procedures for the establishment of residue limits of pharmacologically active substances in foodstuffs of animal origin, repealing council regulation (EEC) No.2377/90 and amending directive 2001/82/EC of the European parliament and of the council and regulation (EC) No. 726/2004 of the European parliament and of the council. Of?cial Journal of the European Union., L152;11-22.

5. European Commission. (2010) Commission regulation (EU) No. 37/2010 of 22 December 2009: on pharmacologically active substances and their classi?cation regarding maximum residue limits in foodstuffs of animal origin. Of? cial Journal of the European Union., L15 ; 1-72.

6. Aguilera-Luiz, M. M., Vidal, J. L. M., Romero-González, R., and Frenich, A. G. (2008) Multi-residue determination of veterinary drugs in milk by ultra-high-pressure liquid chromatography-tandem mass spectrometry. Journal of ChromatographyA., 1205 ; 10-16.

7. Bohm, D. A., Stachel, C. S., and Gowik, P. (2009) Multimethod for the determination of antibiotics of different substance groups in milk and validation in accordance with Commission Decision 2002/657/EC. Journal of Chromatography A., 1216: 8217-8223.

8. Gaugain-Juhel, M., Delépine, B., Gautier, S., Fourmond, M. P., Gaidin, V. and HurtaudPessel, D. (2009) Validation of a liquid chromatography-tandem mass spectrometry screening method to monitor 58 antibiotics in milk: a qualitative approach. Food Additives and Contaminants., 26: 1459-1471.

9. Junza, A., Amatya, R., Barrón, D., and Barbosa, J. (2011) Comparative study of the LCMS/MS and UPLC-MS/MS for the multi-residue analysis of quinolones, penicillins and cephalosporins in cow milk, and validation according to the regulation 2002/657/EC. Journal of Chromatography B., 879: 2601-2610.

10. Kaufmann, A. (2009) Validation of multiresidue methods for veterinary drug residues; related problems and possible solutions. Analytica Chimica Acta., 637: 144-155.

11. Ortelli, D., Cognard, E., Jan, P. and Edder, P. (2009) Comprehensive fast multiresidue screening of 150 veterinary drugs in milk by ultra-performance liquid chromatography coupled to time of ?ight mass spectrometry. Journal of Chromatography B., 877: 2363-2374.

12. Stolker, A. A. M., Rutgers, P., Oosterink, E., Lasaroms, J. J. P., Peters, R. J. B. and Van Rhijn, J. A. (2008) Comprehensive screening and quanti?cation of veterinary drugs in milk 
using UPLC-ToF-MS. Analytical and Bioanalytical Chemistry., 391:2309-2322.

13. Cinquina, A. L., Longo, F., Anastasi, G., Giannetti, L. and Cozzani, R. (2003) Validation of a high-performance liquid chromatography method for the determination of oxytetracycline, tetracycline, chlortetracycline and doxycycline in bovine milk and muscle. Journal of Chromatography A., 987(1-2): 227-233.

14. Fritz, J. W. and Zuo, Y. (2007) Simultaneous determination of tetracycline, oxytetracycline, and 4-epitetracycline in milk by high-performance liquid chromatography. Food Chemistry., 105(3): 1297-1301.

15. Bohm, D. A., Stachel, C. S., and Gowik, P. (2009) Multimethod for the determination of antibiotics of different substance groups in milk and validation in accordance with Commission Decision 2002/657/EC. Journal of Chromatography A., 1216: 8217-8223.

16. Le Bizec, B., Pinel, G., and Antignac, J. P. (2009) Options for veterinary drug analysis using mass spectrometry. Journal of Chromatography A., 1216, 8016-8034.

17. Stolker, A. A. M., Zuidema, T., and Nielen, M. W. F. (2007) Residue analysis of veterinary drugs and growth-promoting agents. Trends in Analytical Chemistry., 26: 967-979.

18. Turnipseed, S. B., Andersen, W. C., Karbiwnyk, C. M., Madson, M. R., and Miller, K. E. (2008) Multi-class, multiresidue liquid chromatography/tandem mass spectrometry screening and con? rmation methods for drug residues in milk. Rapid Communications in Mass Spectrometry., 22: 1467-1480.

19. Franek, M., and Diblikove, I. (2006) Broad-speci?city immunoassays for sulfonamide detection: immunochemical strategy for generic antibodies and competitors. Analytical Chemistry., 78: 1559-1567.

20. Lamar, J., and Petz, M. (2007) Development of a receptorbased microplate assay for the detection of beta-lactam antibiotics in different food matrices. Analytica Chimica
Acta., 586: 296-303.

21. Pastor-Navarro, N., Maquieira, A., and Puchades, R. (2009) Review on immunoanalytical determination of tetracycline and sulfonamide residues in edible products. Analytical and Bioanalytical Chemistry., 395: 907-920.

22. Toldrá, F., and Reig, M. (2006) Methods for rapid detection of chemical and veterinary drug residues in animal foods. Trends in Food Science and Technology., 17: 482-489.

23. Zhang, H., and Wang, S. (2009) Review on enzyme-linked immunosorbent assays for sulfonamide residues in edible animal products. Journal of Immunological Methods., 350: $1-13$.

24. Navratilova, P., Borkovcova, I., Dračkova, M., Janštova, B., and Vorlova, L. (2009) Occurrence of tetracycline, chlortetracycline, and oxytetracycline residues in raw cow's milk, Czech J. Food Sci., 27: 379-385.

25. Elizabeta, D., Zehra, H., Biljana, S., Pavle, S. and Risto, V. (2011) Screening of veterinary drug residues in milk from individual farms in Macedonia. Mac. Vet. Rev. 34(1): 5 - 13.

26. Alomirah, H., Al-Mazeedi, H., Al-Zenki, S., Al-Aati, T., AlOtaibi, J., Al-Batel, M. and Sidhu, J. (2007) Pevalence of antimicrobial residues in milk and dairy products in the state of Kuwait. Journal of Food Quality., 30: 745-763.

27. Bilandžić, N., Solomun, B., Varenina, K.I. and Jurković, Z. (2011) Concentrations of veterinary drug residues in milk from individual farms in Croatia. Veterinary drug residues in milk, Mljekarstvo., 61 (3),: 260-267.

28. Zhang, Y. D., Zheng, N., Han, R. W., Zheng, B. Q., Yu, Z. N., Li, S. L., Zheng, S. S. and Wang, J. Q. (2014) Occurrence of Tetracyclines, Sulfonamides, Sulfamethazine and Quinolones in Pasteurized milk and UHT milk in China's Market. Food Control., 36(1):238-242.

29. Unusan, N. (2009) Occurrence of chloramphenicol, streptomycin and tetracycline residues in ultra-heattreatment milk marketed in Turkey. Int J Food Sci Nutr., 60(5): 359-64.

$* * * * * * * *$ 